\title{
CEsifo WORKING

\section{Division of Labor and the Organization of Knowledge in Production: A Laboratory Experiment}

Victor Klockmann, Alicia von Schenk, Ferdinand A. von Siemens 


\section{Impressum:}

CESifo Working Papers

ISSN 2364-1428 (electronic version)

Publisher and distributor: Munich Society for the Promotion of Economic Research - CESifo

$\mathrm{GmbH}$

The international platform of Ludwigs-Maximilians University's Center for Economic Studies and the ifo Institute

Poschingerstr. 5, 81679 Munich, Germany

Telephone +49 (0)89 2180-2740, Telefax+49 (0)89 2180-17845, email office@cesifo.de

Editor: Clemens Fuest

https://www.cesifo.org/en/wp

An electronic version of the paper may be downloaded

- from the SSRN website: www.SSRN.com

- from the RePEc website: $\quad$ www.RePEc.org

- from the CESifo website: https://www.cesifo.org/en/wp 


\title{
Division of Labor and the Organization of Knowledge in Production: A Laboratory Experiment
}

\begin{abstract}
Following Garicano (2000), we consider groups whose members decide what knowledge to acquire and how to use this knowledge in production. If efficient production requires common knowledge, all group members should become workers and acquire common knowledge. But if efficient production requires diverse knowledge, one group member should become manager, acquire rare knowledge, and stand ready to help the other workers. In our laboratory experiment, we find that most groups eventually manage to coordinate on an efficient division of labor. Still, we find substantial adoption frictions. Coordination takes time, and some groups coordinate on an inefficient division of labor, probably because they do not understand what organization of knowledge is most efficient.
\end{abstract}

JEL-Codes: C720, C920, D200, L230, M200.

Keywords: knowledge, division of labor, organizational economics.

Victor Klockmann

Goethe University Frankfurt

Germany - 60323 Frankfurt

klockmann@econ.uni-frankfurt.de
Alicia von Schenk

Goethe University Frankfurt

Germany - 60323 Frankfurt

vonSchenk@econ.uni-frankfurt.de

Ferdinand A. von Siemens*

Goethe University Frankfurt

Germany - 60323 Frankfurt

vonsiemens@econ.uni-frankfurt.de

*corresponding author

December 2020 


\section{Introduction}

We study whether coordination problems might prevent groups from adopting an efficient division of labor. We consider the optimal acquisition and use of knowledge in organizations as in Garicano (2000). He argues that solving production problems requires knowledge. Workers are directly involved in the production and acquire the most frequently needed knowledge to solve their problems. Managers specialize in rare knowledge and stand by to help workers with problems they cannot solve on their own. The optimal organization of knowledge considers the following tradeoff. On the one hand, managers reserve time to support and communicate with workers, time they cannot directly dedicate to production. On the other hand, managers employ rare knowledge efficiently because they can apply it to help several workers down the line. Division of labor - having managers and workers - is efficient if the production requires diverse knowledge.

Garicano (2000) describes an optimal division of labor within organizations. However, it is far from obvious that organizations always manage to adopt an efficient organization of knowledge. Becker \& Murphy (1992) indeed argue that coordination problems might limit the division of labor within organizations. On page 1138, they say "Modern work on principal-agent conflicts, free-riding, and the difficulties of communication implies that the cost of coordinating a group of complementary specialized workers grows as the number of specialists increases."

In our experiment, we empirically study the argument by Becker \& Murphy (1992) in the setup of Garicano (2000). To be more precise, we explore whether, without the possibility to communicate, coordination problems might impede an efficient organization of knowledge. We consider groups of three who stay together for twenty rounds. In each round, all group members simultaneously choose whether to acquire abstract orange or silver knowledge. They also decide whether to become workers who work on abstract problems or managers who reserve all their time for helping workers. In our treatment Diverse-Knowledge, both silver and orange knowledge is required to solve the vast majority of problems. A particular organization of knowledge, High-Division-of-Labor, is then optimal, with one manager and two workers, the workers acquiring the more common orange knowledge, and the manager specializing in the less common silver knowledge. In our treatment Common-Knowledge, orange knowledge alone is sufficient to solve the vast majority of problems. Low-Division-of-Labor is then optimal, with three workers all acquiring orange knowledge. 
Our data show that most groups eventually coordinate on the efficient division of labor. In the last round of Diverse-Knowledge, $64 \%$ of the groups coordinate on High-Division-of-Labor, and $14 \%$ coordinate on Low-Division-of-Labor. In the treatment Common-Knowledge, $7 \%$ of the groups coordinate on High-Division-of-Labor and $71 \%$ coordinate on Low-Divisionof-Labor. The remaining groups are uncoordinated. These differences in the organization of knowledge are statistically significant. However, there are substantial adoption frictions: organizations need time to establish an efficient division of labor. In the first round, $93 \%$ of all groups do not manage to coordinate on any meaningful division of labor in either treatment. There are no systematic differences in successful coordination for the first four rounds. And some groups remain uncoordinated throughout.

Our data suggest that coordination problems delay or even prevent the adoption of an efficient organization of knowledge. To investigate whether groups find it harder to coordinate on more division of labor, we chose parameters such that in the treatment Common-Knowledge, Low-Division-of-Labor is the unique Nash equilibrium. In the treatment Diverse-Knowledge, both Low-Division-of-Labor and High-Division-of-Labor are Nash equilibria, although the latter is more efficient. Groups might, therefore, fail to coordinate on the efficient Nash equilibrium. Further, High-Division-of-Labor requires agreement on who should be a manager, making it more challenging to achieve. Our data reveal that groups do not find it more difficult to coordinate on High-Division-of-Labor. In the last round, $64 \%$ and $71 \%$ of the groups adopt the efficient organization of knowledge in our treatments, and this small difference is not statistically significant. Groups do not find it more difficult to adopt more complex organizational structures.

Instead, we unexpectedly find that some groups consistently coordinate on a high but inefficient division of labor. Looking at the transition between rounds, $88 \%$ of the groups with Low-Division-of-Labor keep this inefficient organization of knowledge in the treatment Diverse-Knowledge. Maybe these groups are stuck in an inefficient equilibrium due to coordination problems. But also $87 \%$ of the groups with High-Division-of-Labor keep this inefficient organization of knowledge in the treatment Common-Knowledge. High-Divisionof-Labor is not even a Nash equilibrium in this treatment.

This finding raises the question of why some groups coordinate on the wrong organization of knowledge. Our data suggests that some groups believe the wrong organization of knowledge 
to maximize efficiency. In our text analysis of the final questionnaire, we find that many participants consider their group outcome to be efficient, although their group consistently coordinates on an inefficient division of labor. Between $56 \%$ and $67 \%$ of the participants in groups with an inefficient organization of knowledge seem to be satisfied with the outcome, which suggests that participants do not see how easily they could have increased their payoffs by changing their behavior.

Summarizing, we find that most groups eventually adopt the efficient division of labor. The results show that Garicano (2000) does not only characterize what organization of knowledge is efficient; it also has empirical relevance in our experimental setup. However, there are adoption frictions because almost all groups are uncoordinated in the first round, and some remain uncoordinated throughout the experiment. Although there exist coordination problems, we do not find that groups have a harder time coordinating on more complicated organizational forms. This result is inconsistent with Becker \& Murphy (1992). We instead find that some groups consistently coordinate on a complex but inefficient organization of knowledge, even if unilateral deviations would increase the monetary payoffs of all. This misguided coordination seems to be driven by a lack of understanding of what constitutes the most efficient organizational form. Our results suggest that organizations must not only overcome coordination problems to establish an efficient organization of knowledge; they must also ensure a common understanding of what they want to achieve.

\section{Literature}

The motivation for our study was to explore whether coordination problems might impede an efficient organization of knowledge. We thereby contribute to the experimental literature on coordination problems in organizations; see, for example, van Huyck, Battalio \& Beil (1990), van Huyck, Gillette \& Battalio (1992), Brandts \& Cooper (2006), Weber (2006), Brandts \& Cooper (2007), Brandts, Cooper \& Weber (2015), and the papers cited in Camerer \& Weber (2013). These experiments focus on different strategic situations, in particular symmetric versions of the stag hunt. Their experimental designs are less suitable to explore the organization of knowledge, which requires asymmetric division of labor in a particular decision environment. 
Although our decision environment is still relatively simple, participants need to figure out what division of labor they want to coordinate on. This feature relates our study to the experimental literature on spontaneous order, which explores the endogenous emergence of specialization and division of labor. In Crockett, Smith \& Wilson (2009), participants must discover and implement a self-enforcing exchange system before they can exploit the gains to specialization. The authors find that many, but far from all, participants learn to specialize and coordinate production. Based on the same experimental paradigm, Kimbrough, Smith \& Wilson (2010) explore the importance of property rights. They find that efficiency is higher if property rights are formally protected. However, some groups without formal property rights develop informal conventions that prevent theft; these groups can reap the gains to specialization. Kimbrough, Smith \& Wilson (2008) show that a history of formal property rights fosters impersonal exchange and long-distance trade. Smyth \& Wilson (2019) study the division of labor within and across groups. They observe that groups are quite adept at realizing internal coordination, but efficient specialization and trade across groups are harder to establish. Georgalos \& Hey (2020) investigate whether group members coordinate in a production environment with returns to specialization. They do not find evidence for spontaneous order and optimal division of labor without communication.

Our experimental design differs from the above studies in many aspects. Maybe the most important distinction is that our decision environment is still relatively simple. In particular, the labor-market framing with managers and workers emphasizes possible returns to specialization, which could explain why groups do not find it more difficult to adopt the more complex High-Division-of-Labor than Low-Division-of-Labor in our treatment Diverse-Knowledge. We nevertheless see that some groups in our experiment fail to discover the most efficient organizational form. Our results, therefore, complement the above studies, which show that lack of ideas or understanding is an essential impediment to the emergence of spontaneous order.

Finally, our experimental results are consistent with arguments and findings in the literature on firm heterogeneity. Firms outside of the laboratory diverge widely in their productivity, both within and across countries; see Syverson (2004), Foster, Haltiwanger \& Syverson (2008), Hall \& Jones (1999). Bloom \& Van Reenen (2010) argue that this heterogeneity arises because firms differ in their organization of the production process. In our experiment, we find that groups adopt different organization of knowledge and thereby consistently 
differ in their efficiency. Further, lack of understanding hinders the adoption of an efficient organizational form in our experiment. This result resonates with Bloom, Eifert, Mahajan, McKenzie \& Roberts (2013) who summarize their field experiment on good managerial practice by saying that "... firms were not implementing best practices on their own because of lack of information and knowledge" (p.44). As compared to an economic experiment, lack of knowledge is probably a much larger problem in the field, where organizational structures and production processes are infinitely more complex. However, some participants, even in our simple and stylized setup, fail to discover the most efficient organizational form. This result only emphasizes the importance of informational frictions or bounded rationality for the heterogeneity in firm productivity in the field.

\section{Theory}

In our adaptation of Garicano (2000), we consider groups of three individuals. Individuals simultaneously decide whether they want to be workers or managers. Workers engage directly in production and thereby face $m$ problems. The solution for $p \geq m / 2$ of these problems requires what we call orange knowledge. The remaining $m-p$ problems require what we call silver knowledge. Workers themselves can solve the problems for which they have previously acquired the relevant knowledge. They can ask managers for help with those problems they cannot solve alone. Managers do not engage directly in production themselves and thus do not face their own problems. Instead, they stand by to help workers with their unsolved problems. They can solve them if they are asked for help and have the relevant knowledge. Each group member, manager or worker, can solve up to $m$ problems. All group members share the total group payoff equally so that incentives are fully aligned. Solving $k$ problems generates a payoff of $r k$ for all group members.

Asking for help creates communication costs $c$ for all group members. Given workers ask for help, the communication costs $c$ do not depend on the number of problems for which workers need support. The costs also do not depend on whether workers find somebody with the relevant knowledge to help them. The idea is that workers must go around and ask group members whether they have the relevant knowledge to help them with their unsolved problems. And help requests disrupt the production process also if nobody has the knowledge to help. 
Our theoretical setup is based on the following arguments and assumptions. We assume that group members can communicate knowledge in the sense that one group members can ask for - and get help by - other group members. But following Garicano, we consider knowledge that is specific and resides with people. On page 875, Garicano argues that "Production know-how is, however, often tacit and thus is "embodied" in individuals. Knowing if someone knows the solution to a problem inevitably involves asking that person." Following Becker \& Murphy (1992), we further assume that there are some limits to communication, which might generate coordination problems. In particular, we assume that group members cannot communicate what knowledge each group member should acquire, and also which role to take on in the organization. Our theory might, thus, be related more to young organizations - like start-ups - who must still figure out the precise division of labor among members. Our setup is less suitable to study long-established organizations in which an owner ensures coordination by assigning roles and knowledge acquisition. Finally, although workers could discuss problems with each other, they cannot provide mutual help because they are busy solving their own problems. Only managers have the time to help others so that an efficient organization of knowledge might specify not only knowledge specialization but also different roles within the organization.

The timing of the strategic interaction can be summarized as follows:

1. Group members simultaneously choose whether to become managers or workers.

They also acquire orange or silver knowledge at zero costs.

2. Each worker faces $m$ problems.

$p$ problems require orange knowledge to be solved, the others silver knowledge.

3. Workers solve problems for which they hold the relevant knowledge.

They can ask for help for their unsolved problems.

They do not know the roles and knowledge of the other group members at this moment.

4. Managers work on the problems for which help was requested.

They can solve the problems for which they hold the relevant knowledge.

They have capacity to solve at most $m$ problems.

5. $k$ solved problems generate revenue of $r k$ for each group member.

Asking for help generates communication costs $c$ for each group member. 
Two organizations of knowledge are potentially efficient: we call them Low-Division-of-Labor and High-Division-of-Labor. The efficient organization of knowledge always forms a Nash equilibrium in our common-interest game. But there might simultaneously co-exist inefficient Nash equilibria. In the following, we thus first describe the two organizations of knowledge and the conditions under which they form a Nash equilibrium.

We first consider Low-Division-of-Labor in which all three group members become workers and acquire orange knowledge. We still have some division of labor in this organization of knowledge because workers work on different problems. Also, note that workers form an organization because they share payoffs. There is the following result.

Result 1 (Low-Division-of-Labor-Equilibrium) There always exists a Nash equilibrium in which (i) all group members become workers, (ii) workers acquire the more frequent knowledge, and (iii) workers never send any help requests.

This result is based on the following argument. In equilibrium, workers know that it makes no sense to ask for help for their unsolved problems, simply because there are no managers who can provide support, and asking for help is costly. The optimal choice is then to learn the more frequent problem class orange. No group member has any incentives to become a manager because nobody ever asks for help in equilibrium.

We next derive the conditions under which our other organization of knowledge, HighDivision-of-Labor, forms a Nash equilibrium. There is then one manager who learns problem class silver, two workers who each learn problem class orange, and both workers ask the manager for help for their unsolved silver problems.

Result 2 (High-Division-of-Labor-Equilibrium) If and only if the communication costs c are sufficiently small,

$$
c \leq(m-p) r
$$

and the number $p$ of problems in the more frequent problem class orange is sufficiently small,

$$
p \leq \frac{2}{3} m
$$

there exists a Nash equilibrium in which (i) one group member becomes a manager and two group members become workers, (ii) the manager acquires the less and the workers acquire the more frequent knowledge, and (iii) workers ask their manager for help for the problems they cannot solve. 
This result is based on the following argument. First, we derive the condition under which a worker with orange knowledge optimally requests help for the $m-p$ of silver problems that he cannot solve. Not requesting help contributes zero to the group. Requesting help generates costs $c$, but in equilibrium, the manager has the silver knowledge. It is optimal to request help if and only if the communication costs $c$ fall below the revenue $(m-p) r$ generated by the manager solving the silver problems. The comparison generates condition (1). Note that the manager has enough capacity to help both workers with their silver problems because silver is the rarer problem class, and the manager can solve up to $m$ problems.

Second, we check that a worker with orange knowledge has no incentives to acquire the silver knowledge. Given that there is a manager who learns silver, all problems of a worker are solved in equilibrium, and he therefore contributes

$$
m r-c
$$

to the total net payoff of the group. The worker could deviate and acquire the silver knowledge to solve the $m-p$ silver problems. For the orange problems, he optimally requests no help because the manager in equilibrium only learns the silver knowledge and thus cannot help. The worker then contributes

$$
(m-p) r
$$

to the total net payoff of the group. It is consequently optimal to learn orange and ask for help for the silver problems if and only if

$$
m r-c \geq(m-p) r
$$

or $c \leq p r$. Orange problems are more frequent than silver problems, so that this condition imposes weaker restrictions on the communication costs $c$ than condition (1). It is, therefore, optimal to ask for help for the silver problems. Note that a worker never has incentives to become a second manager. 
Thirdly, we consider the manager who in equilibrium acquires the silver knowledge. The manager in his role has no incentives to learn orange because he never receives any help requests for orange problems. However, the manager might have incentives to become a worker. The manager with silver knowledge contributes

$$
2(m-p) r
$$

to the group payoff because his knowledge always generates return $r$ for each silver problem forwarded by the workers. If the manager becomes a worker, there are no managers left in the firm, and he optimally acquires orange knowledge to contribute $p r$ to the group payoff. Comparing this contribution to his equilibrium contribution $2(m-p) r$, it is optimal for the manager to keep his role if and only if condition (2) holds. Intuitively, using a manager specialized in solving rare problems is efficient if and only if he can apply his knowledge to a sufficiently large number of problems. Note that if a manager deviates to becoming a worker, this is not seen by the workers, who consequently still send their help requests, thereby generating communication costs.

Note that there might also exist a Nash equilibrium in pure strategies in which two workers acquire knowledge for the silver problem class, ask the manager for help for their orange problems, while the manager acquires the orange knowledge. Such "Miscoordinated-HighDivision-of-Labor" is always less efficient than Low-Division-of-Labor. The reason is that the manager can at most solve $m$ problems and has not the capacity to solve the $2 p$ orange problems forwarded by the workers. In the following analysis, we ignore this possible equilibrium. We observe Miscoordinated-High-Division-of-Labor in only $0.18 \%$ of the cases in the experiment.

We next investigate whether there might be situations in which High-Division-of-Labor forms a Nash equilibrium and generates higher total group payoffs than Low-Division-of-Labor. There is the following result. 
Result 3 (Multiple Equilibria and Efficiency) If and only if the communication costs $c$ are sufficiently small,

$$
c \leq \frac{r m}{4}
$$

and the number $p$ of problems in the more frequent problem class orange is sufficiently small,

$$
p \leq \frac{2}{3}\left(m-\frac{c}{r}\right),
$$

High-Division-of-Labor is an equilibrium and more efficient than Low-Division-of-Labor.

This result is based on the following argument. The total net group payoffs are

$$
3 p r
$$

under Low-Division-of-Labor and

$$
2 p r-2 c+2(m-p) r=2 m r-2 c
$$

under High-Division-of-Labor. High-Division-of-Labor is more efficient than Low-Divisionof-Labor if and only if

$$
p \leq \frac{2 m r-2 c}{3 r}
$$

which yields condition (8). We next show that High-Division-of-Labor is an equilibrium whenever it is more efficient than Low-Division-of-Labor, which is equivalent to (8) implying (1) and (2). First, note that orange problems are more frequent, $p \geq m / 2$. Condition (8) can therefore be satisfied only if the right hand side is larger than $m / 2$. The comparison yields $c \leq r m / 4$ or condition (7). Because $p \geq m / 2$ we have $(m-p) r \leq r m / 2$. Thus, (7) implies (1) and workers optimally ask for help for their silver problems. Second, condition (8) directly implies condition (2). The reason is that groups might be trapped in inefficiently high division of labor because workers still ask for help and generate communication costs if the manager switches to become a worker. If the efficiency gains comparing Low-Divisionof-Labor to High-Division-of-Labor are small as compared to the communication costs, an inefficient High-Division-of-Labor is an equilibrium. However, we will not focus on this possible friction, which cannot arise given the parameters in our experiment.

There are, therefore, situations in which High-Division-of-Labor is an equilibrium and more efficient than Low-Division-of-Labor. However, High-Division-of-Labor requires quite a lot of coordination among the group members. It is not apparent how fast group members manage to coordinate on the more efficient High-Division-of-Labor and whether they manage to do so at all. We investigate this in the following experiment. 


\section{Experiment}

The experiment essentially implements the theoretical setup described above. We randomly assign participants to groups with three members that remain the same throughout the entire session. We label each group member according to a geometric figure (circle, square, and triangle) for identification. The groups can earn points by repeatedly solving problems over 20 rounds. The timing of the strategic interaction in each round follows the above described theoretical setup. Workers are assigned $m=100$ problems, out of which $p \geq 50$ problems belong to the orange and the others to the silver knowledge class. Our problems are completely abstract - we do not use a real effort task in which participants have to solve real problems. Acquiring the relevant abstract knowledge simply allows participants to solve the corresponding problems.

The reward for solving a problem is 10 points. Communication costs are 25 points and do not depend on the number of problems workers need help for. Given this parametrization, High-Division-of-Labor is an equilibrium and more efficient than Low-Division-of-Labor if and only if $p$ falls below 65 . To study whether participants manage to coordinate on the efficient equilibrium, we consider two treatments. In the treatment Common-Knowledge, 75 out of the 100 problems are in the orange class. Groups then earn 2250 points with Low-Division-of-Labor and 1950 points with High-Division-of-Labor. Low-Division-of-Labor is efficient and the only Nash equilibrium. In our treatment Diverse-Knowledge, 55 out of the 100 problems are in the orange class. Groups then earn 1650 points with Low-Divisionof-Labor and 1950 points with High-Division-of-Labor. High-Division-of-Labor now also forms an equilibrium, and this equilibrium is more efficient than Low-Division-of-Labor. The parameters ensure that the incentives to coordinate on the efficient organization of knowledge are the same in both treatments: the absolute difference between High-Division-of-Labor and Low-Division-of-Labor is 300 points. Group members share the total group payoff equally so that their incentives are fully aligned.

We conducted the experiment at the Frankfurter Laboratory for Experimental Economic Research (FLEX). We recruited subjects from a pool of students from Goethe University Frankfurt using ORSEE (Greiner 2015). In total, we ran eight sessions with 168 participants and 56 groups, all in April 2019. We randomly assigned groups to treatments within sessions to preclude session effects, and we had 28 groups in each treatment. We implemented the experiment in oTree by Chen, Schonger \& Wickens (2016) and hosted it on a Heroku 
server. Each session lasted between 45 to 60 minutes. Participants filled out a standard questionnaire towards the end of the experiment, eliciting age, gender, and field of study. We also asked participants to explain their behavior in the experiment in a free form text field.

We randomly chose one round for payment to avoid wealth effects. The conversion rate was 50 eurocents per 100 points, so that groups could increase their earnings by 1.50 euros with the adoption of the most efficient organization of knowledge. Participants earned between 5 euros and 16.25 euros. The overall average pay was 14.24 euros, including 5 euros show-up fee. The experimental instructions can be found in Appendix C.

\section{Empirical results}

We first explore whether groups eventually adopt an efficient organization of knowledge, given the parameters in our treatments. We then study two mechanisms driving the observed adoption frictions: coordination problems and a lack of understanding of what organization of knowledge maximizes efficiency.

\subsection{Efficient division of labor}

If groups coordinate on the efficient organization of knowledge as described by Garicano (2000), we should see Low-Division-of-Labor in Common-Knowledge and High-Division-ofLabor in Diverse-Knowledge. We say that groups coordinate on Low-Division-of-Labor if all group members are workers, acquire orange knowledge, and send no help requests for their unsolved silver problems. We say that groups coordinate on High-Division-of-Labor if two group members are workers and one is a manager, workers acquire orange knowledge, the manager acquires silver knowledge, and workers send help requests for their unsolved silver problems. We classify all other groups as uncoordinated. 


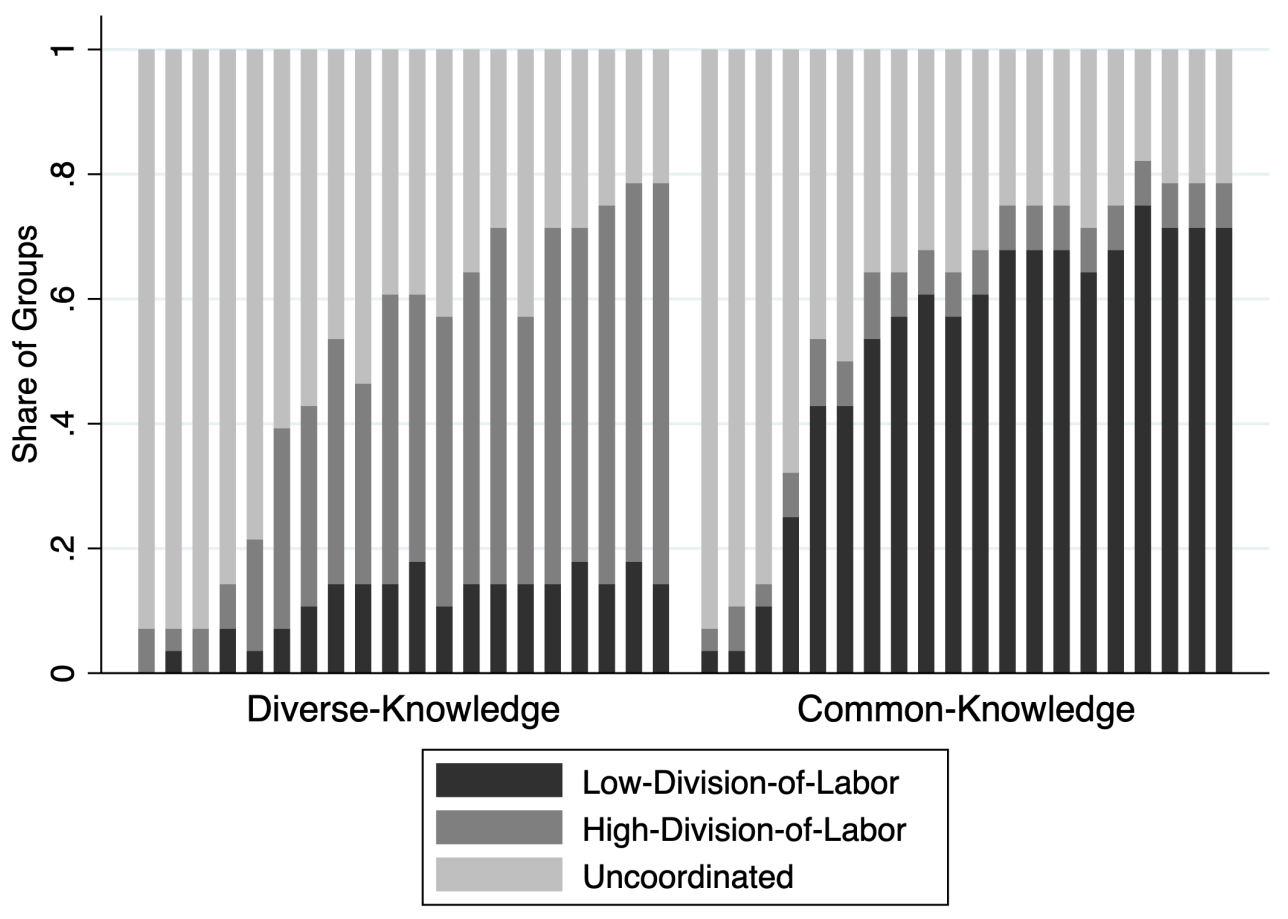

Figure 1: Coordination Over Time.

Note: Distribution of groups with different organizations of knowledge, for all rounds and treatments. In Low-Division-of-Labor and High-Division-of-Labor, workers also make the appropriate help requests.

Figure 1 plots organization of knowledge over time. In the last round in Diverse-Knowledge, $64 \%$ of the groups coordinate on High-Division-of-Labor, $14 \%$ coordinate on Low-Divisionof-Labor, and the remaining $21 \%$ of the groups are uncoordinated. In Common-Knowledge, $7 \%$ of the groups coordinate on High-Division-of-Labor, $71 \%$ coordinate on Low-Divisionof-Labor, and $21 \%$ are uncoordinated. The differences in the organization of knowledge are highly significant ( $p$-value less than 0.001 from a Chi-Square test). 


\begin{tabular}{lcc}
\hline \hline & Diverse-Knowledge & Common-Knowledge \\
\hline Consistent coordination in last 5 Rounds & & \\
\hline Uncoordinated & 0.39 & 0.32 \\
Low-Division-of-Labor & 0.14 & 0.61 \\
High-Division-of-Labor & 0.46 & 0.07 \\
\hline \hline
\end{tabular}

Table 1: Coordination at the End of the Experiment.

Note: Fractions of groups with consistent organizations of knowledge. Groups consistently coordinate on a particular organization of knowledge if and only if the latter is adopted in all of the last five rounds.

Our aggregate analysis cannot tell whether the observed patterns reflect stable coordination within groups. We classify groups as consistently coordinated on Low-Division-of-Labor if they coordinate on Low-Division-of-Labor in all last five rounds. We categorize groups as consistently coordinated on High-Division-of-Labor analogously. We label all other groups as being uncoordinated. Table 1 reveals that groups in Diverse-Knowledge consistently coordinate more often on High-Division-of-Labor than Low-Division-of-Labor (46\% versus 14\%). Groups in Common-Knowledge consistently coordinate more often on Low-Division-of-Labor than High-Division-of-Labor (61\% versus 7\%). The difference in the organization of knowledge is highly significant ( $p$-value less than 0.001 from a Chi-Square test). Looking at both aggregate and group-level behavior, most groups eventually manage to organize knowledge efficiently according to Garicano (2000).

\subsection{Adoption frictions}

We next discuss frictions in the adoption of the optimal organization of knowledge. Figure 1 shows that the treatment difference in the organization of knowledge emerges only over time. In the first round, $93 \%$ of all groups are uncoordinated in both treatments, and there are no significant differences in the organization of knowledge across treatments ( $p$-value of 0.51 ). The emerging differences remain insignificant for the first four rounds ( $p$-values weakly larger than 0.18). From round five onwards, the differences in the organization of knowledge are highly significant ( $p$-values less than 0.01 ). Furthermore, $21 \%$ of all groups are uncoordinated in the last round. Table 1 confirms that not all groups manage to consistently coordinate: over the last five rounds, the fraction of uncoordinated groups is $39 \%$ in Diverse-Knowledge and $32 \%$ in Common-Knowledge. Groups take time to adopt the efficient organization of knowledge, and some groups do not manage to establish an efficient division of labor at all over the 20 rounds. There are adoption frictions. 
The observed adoption frictions could arise because participants fail to coordinate in their attempt to form an efficient organization of knowledge or need to figure out the most efficient organization of knowledge. In the following, we explore which of these frictions matter in the adoption process.

\subsubsection{Coordination problems}

Even groups that eventually get it right need time to adopt an efficient division of labor, strongly suggesting that coordination issues matter. However, in the following we argue that coordination problems alone do not seem to be driving the adoption frictions. First, we do not find that coordination on more division of labor - more complex organizational structures - is more difficult. Second, we see that some groups consistently coordinate on the wrong organization of knowledge. We next discuss these findings in more detail.

Concerning our first finding - coordination on the more complex organizational structure is not more difficult - we compare adoption frictions in our treatments. Low-Division-of-Labor is a simple organizational structure and the unique Nash equilibrium in Common-Knowledge. There are multiple Nash equilibria in Diverse-Knowledge, with the more complicated HighDivision-of-Labor being most efficient. The multiplicity of equilibria alone should make coordination more difficult in Diverse-Knowledge. Further, High-Division-of-Labor is more challenging to achieve because it requires more division of labor and groups need to figure out who should be manager. If coordination failure alone cause the adoption problems, we should observe better coordination on the efficient organization of knowledge in Common-Knowledge than in Diverse-Knowledge.

This is not what we find. Looking at the first round, $7 \%$ of the groups adopt the efficient High-Division-of-Labor in Diverse-Knowledge, while $4 \%$ of the groups adopt the efficient Low-Division-of-Labor in Common-Knowledge. Looking at the last round, $64 \%$ and $71 \%$ of the groups assume the efficient organization of knowledge in Diverse-Knowledge and Common-Knowledge. Fisher-exact tests show that these small differences are not statistically significant ( $p$-values of 1.00 and 0.78 ).

Concerning our second finding - some groups consistently coordinate on an inefficient organizational form - we look at how the organization of knowledge evolves within groups. Table 2 shows the number of uncoordinated groups, groups that coordinate on Low- 


\begin{tabular}{lccc}
\hline \hline & \multicolumn{3}{c}{ Organizational Form in the Current Round } \\
\cline { 2 - 4 } & Uncoordinated & Low-Division-of-Labor & High-Division-of-Labor \\
\hline Diverse-Knowledge & & & 35 \\
\hline Uncoordinated in Previous Round & 231 & 52 & 0 \\
Low-Division in Previous Round & 7 & 0 & 176 \\
High-Division in Previous Round & 19 & 37 & 6 \\
\hline Common-Knowledge & & 253 & 0 \\
\hline Uncoordinated in Previous Round & 179 & 1 & 33 \\
Low-Division in Previous Round & 19 & 4 & \\
High-Division in Previous Round & 49 & & \\
\hline \hline
\end{tabular}

Table 2: Evolution of Coordination.

Note: Numbers of groups being uncoordinated, coordinated on Low-Division-of-Labor, or High-Division-ofLabor, in the current round, and depending on the organization of knowledge in the previous round, for both treatments.

Division-of-Labor, or groups that coordinate on High-Division-of-Labor, conditional on what happened in the previous round, from the second round onwards. We have one observation per group per round.

We find that $83 \%$ and $81 \%$ of the uncoordinated groups remain uncoordinated in DiverseKnowledge and Common-Knowledge. These numbers confirm that coordination issues exist because some groups remain uncoordinated, which is inefficient. But we also see that some groups coordinate on an inefficient organization of knowledge and remain there. $88 \%$ of the groups with Low-Division-of-Labor in Diverse-Knowledge keep their inefficient organization of knowledge in the next round. These groups might be stuck in an inefficient Nash equilibrium. But also $87 \%$ of the groups with High-Division-of-Labor in Common-Knowledge keep their inefficient organization of knowledge. These groups are not stuck in an inefficient Nash equilibrium, because High-Division-of-Labor is no Nash equilibrium in Common-Knowledge. In fact, the manager could increase the payoff of all group members by unilaterally deviating and becoming a worker with orange knowledge, even if the others continue to send help requests. Figure 2 in Appendix A further illustrates persistent coordination on an inefficient organization of knowledge, showing coordination in each round and for all individual groups. In Diverse-Knowledge, the groups S1-G7, S6-G2, and S8-G1 (and, except for one period, group S3-G6) persistently coordinate on the inefficient Low-Division-of-Labor. In Common-Knowledge, the groups S4-G2 and S7-G6 persistently coordinate on the inefficient High-Division-of-Labor. 


\begin{tabular}{|c|c|c|c|}
\hline & \multicolumn{3}{|c|}{ Organizational Form in the Current Round } \\
\hline & Uncoordinated & Low-Division-of-Labor & High-Division-of-Labor \\
\hline \multirow[t]{2}{*}{ Constant } & $0.81^{* * *}$ & $0.93^{* * *}$ & $0.87^{* * *}$ \\
\hline & $(0.03)$ & $(0.02)$ & $(0.10)$ \\
\hline \multirow[t]{2}{*}{ Uncoordinated Previous Round } & & $-0.76^{* * *}$ & $-0.84^{* * *}$ \\
\hline & & $(0.04)$ & $(0.10)$ \\
\hline \multirow[t]{2}{*}{ Low-Division Previous Round } & $-0.74^{* * *}$ & & $-0.87^{* * *}$ \\
\hline & $(0.04)$ & & $(0.10)$ \\
\hline \multirow[t]{2}{*}{ High-Division Previous Round } & $-0.70^{* * *}$ & $-0.90^{* * *}$ & \\
\hline & $(0.08)$ & $(0.04)$ & \\
\hline \multirow[t]{2}{*}{ Diverse-Knowledge } & 0.03 & -0.05 & 0.03 \\
\hline & $(0.04)$ & $(0.05)$ & $(0.11)$ \\
\hline \multirow[t]{2}{*}{ Uncoord Pre Round $\times$ Diverse } & & -0.08 & 0.06 \\
\hline & & $(0.06)$ & $(0.11)$ \\
\hline \multirow[t]{2}{*}{ Low-Div Pre Round $\times$ Diverse } & 0.02 & & -0.03 \\
\hline & $(0.07)$ & & $(0.11)$ \\
\hline \multirow[t]{2}{*}{ High-Div Pre Round $\times$ Diverse } & -0.04 & 0.02 & \\
\hline & $(0.09)$ & $(0.06)$ & \\
\hline Number of Observations & 1064 & 1064 & 1064 \\
\hline adjusted $R^{2}$ & 0.55 & 0.72 & 0.70 \\
\hline
\end{tabular}

Table 3: Regression Results Coordination.

Note: Results of linear regressions where the dependent variables are dummy variables indicating whether groups adopt particular organizational forms in the current period. The dependent variables indicate whether groups are uncoordinated (first column), coordinate on Low-Division-of-Labor (second column), or coordinate on High-Division-of-Labor (third column), conditional on treatment, organization of knowledge in the last round, and the interaction of the latter. The omitted category corresponds to the dependent variable in Common-Knowledge. Standard errors in parentheses, clustered at the group level. Stars indicate statistical significance at the $10 \%, 5 \%$ and $1 \%$ level.

Regression analysis confirms our impressions. Table 3 reports the results of linear regressions where the dependent variables are dummy variables indicating whether a group adopts a particular organizational form in the current period. In the regression reported in the first column, the dependent variable takes on the value of one if groups are uncoordinated in the current round, and zero otherwise. In the regressions reported in the second and third column, the dependent variables indicate whether groups coordinate on low or high division of labor, respectively. We include data from the second round onwards, take one observation per group per round, and cluster standard errors on the group level. Control variables are the organization of knowledge in the previous round, a treatment dummy for 
Diverse-Knowledge, and the interactions. The constants denote the probability with which groups assume the particular organization of knowledge studied in the respective column if they had that same organizational form in the last round.

The regressions show that groups have a high probability of adopting the same organization of knowledge as in the previous round, and consequently a low probability of transitioning from one particular organization of knowledge to another. The constants are large in absolute value, while the coefficients on the other organizations of knowledge are all negative, large in absolute value, and highly significant ( $p$-values smaller than 0.001). The constants reveal that the probability to remain in the same organizational form is between $81 \%$ and $93 \%$. The probability of adopting a certain organizational form is smaller by at least $70 \%$ if the group has assumed another structure in the previous round. The small and insignificant treatment dummy and interaction terms show that the stability in organizations of knowledge is the same in both treatments ( $p$-values weakly larger than 0.23 ). Because the result holds both for LowDivision-of-Labor and High-Division-of-Labor in both treatments, some groups consistently coordinate on an inefficient organization of knowledge.

\subsubsection{Lack of knowledge}

The analysis so far shows that coordination problems generate some adoption frictions. But groups do not find it harder to adopt more complex organizational structures, and some groups persistently coordinate on the wrong organization of knowledge, suggesting that something else might also be behind the adoption frictions. In the following, we argue that some groups persistently coordinate on the wrong division of labor because they believe the wrong organization of knowledge to be efficient. ${ }^{1}$

To study the importance of such information frictions, we take an exploratory and cautious look at our final questionnaire. In a free-form text field, we ask participants to describe the reasons for their behavior. Many participants freely share thoughts on their experiences in the experiment. For coding, we first created categories based on our initial reading of the texts. "Uncoordinated" and "Coordinated" describe whether the participant considered his group to be coordinated or uncoordinated. "Inefficient" and "Efficient" characterize how the participant evaluated the outcome of the group interaction. "Safety" means that

\footnotetext{
${ }^{1}$ Another driver of the observed adoption frictions could be power preferences, that is, some participants receive extra utility from being the manager. However, we show in Appendix B that power preferences do not affect behavior in our experiment.
} 
the participant tried to generate a safe payoff. Two researchers independently coded a binary variable indicating whether the text falls into one or several of the categories. For example, a text might not refer to coordinated or uncoordinated behavior at all. In this case, the two variables "Uncoordinated" and "Coordinated" would both be coded as zero. The binary variables generated by the two researchers are highly correlated (Spearman' rank correlations of at least 0.63 with $p$-values smaller than 0.001 ). To only consider univocal texts, we generate final binary variables for each category. These variables correspond to the assessments of the two researchers whenever they agree. We code the variables as missing in case of disagreement. The percentage of missing values ranges from less than $1 \%$ for the variable "Uncoordinated" to $18 \%$ for the variable "Coordinated." Table 4 shows how often the texts of participants fall into the six categories, conditional on treatment, and on whether their groups consistently coordinated on some organization of knowledge in the last five rounds.

Coding text messages is always tricky, and it is also not clear that participants truthfully reveal their motivations. However, the data show some definite patterns, suggesting that some groups do not quite understand how they could increase payoffs and, therefore, remain in an inefficient organizational form. $55 \%$ of the participants state that their groups somehow managed to coordinate their actions. The fractions are between $44 \%$ and $70 \%$ for those groups that coordinate on Low-Division-of-Labor or High-Division-of-Labor. However, 35\% and $50 \%$ of the participants in uncoordinated groups consider their groups to be coordinated. These groups might actually be quite well, albeit not perfectly, coordinated. For example, there can be groups consisting of three workers with orange knowledge, in which some send help requests for their silver problems. Sending such help requests is not very expensive, while the potential upside is considerable. However, the data suggest that many participants do not see how easily they could increase payoffs. 


\begin{tabular}{lccc}
\hline \hline & Uncoordinated & Low-Division-of-Labor & High-Division-of-Labor \\
\hline Diverse-Knowledge & & & \\
\hline Uncoordinated & 0.21 & 0.08 & 0.00 \\
Coordinated & 0.50 & 0.44 & 0.70 \\
Inefficient Outcome & 0.23 & 0.30 & 0.00 \\
Efficient Outcome & 0.56 & 0.56 & 0.74 \\
Safety & 0.00 & 0.45 & 0.03 \\
\hline Common-Knowledge & & & 0.00 \\
\hline Uncoordinated & 0.11 & 0.00 & 0.50 \\
Coordinated & 0.35 & 0.61 & 0.00 \\
Inefficient Outcome & 0.12 & 0.04 & 0.67 \\
Efficient Outcome & 0.55 & 0.75 & 0.00 \\
Safety & 0.04 & 0.04 & \\
\hline \hline
\end{tabular}

Table 4: Text Analysis.

Note: Fraction of texts from the final questionnaire that fall into our six categories, conditional on treatment and on their coordination. Our categories try to capture whether participants think that their group was uncoordinated, coordinated, inefficient, efficient, whether somebody in their group exhibited power preferences, and whether they tried to achieve a safe payoff.

Next, we analyze how satisfied participants are with the group outcome. Consider first the participant in groups with an efficient organization of knowledge. $74 \%$ of the participants who coordinated on High-Division-of-Labor in Diverse-Knowledge, and 75\% of the participants who coordinated on Low-Division-of-Labor in Common-Knowledge consider their groups to have found an efficient arrangement. Only $0 \%$ and $4 \%$ seem to be unhappy with the outcome. Those in groups with an efficient organization of knowledge rightly consider the result to be positive. However, more important for our argument are the groups that coordinate on an inefficient organization of knowledge. Of the participants with Low-Division-of-Labor in Diverse-Knowledge, $56 \%$ consider the outcome to be efficient, suggesting that these participants deliberately coordinate on an inefficient organization of knowledge. Only 30\% of the participants with Low-Division-of-Labor in Diverse-Knowledge appear to be unhappy. The text messages of the unhappy participants often suggest that these groups got stuck in a bad equilibrium, from which it was difficult and risky to escape. Indeed, $45 \%$ of these participants state that they wanted to have a safe return and thus became workers with orange knowledge. This result supports the importance of coordination problems and the effects of strategic ambiguity, as documented in the numerous experiments on coordination games. 
We finally consider the two groups who inefficiently coordinate on High-Division-of-Labor in Common-Knowledge. $67 \%$ of these participants believe their organization of knowledge to be efficient, and nobody is unhappy. This high percentage strongly suggests that participants do not understand that they could increase monetary payoffs by unilaterally deviating and becoming a worker with orange knowledge. Further, $55 \%$ and $56 \%$ of the participants in uncoordinated groups view the group outcome quite positively, while only $23 \%$ and $12 \%$ are unhappy. This high level of satisfaction could explain why these groups do not manage to coordinate on some organization of knowledge over the 20 rounds. These participants are not ambitious, or they do not see how easily they could increase their monetary payoffs by changing their behavior. Overall, the questionnaire data shows that many participants are happy with rather inefficient outcomes. The likely explanation is that they do not understand that their organization of knowledge is inefficient.

\section{Conclusion}

In our laboratory experiment, we study whether groups manage to coordinate on an efficient division of labor. We find that most groups eventually adopt the optimal organization of knowledge as characterized by Garicano (2000). However, there are substantial adoption frictions, in particular coordination problems and a misunderstanding of what organization of knowledge is most efficient. Future research could study the role of market competition, which provides groups with more substantial incentives to adopt an efficient organization of knowledge. Market interaction could also spread information about what is efficient because groups might want to imitate successful competitors. It could be interesting to disentangle and measure the relative strength of these effects.

Further, figuring out the optimal organization of knowledge requires coordinated learning and experimentation within groups. In particular, single group members might substantially delay learning if they consistently adopt an inefficient role within the organization. Communication within the group might help to understand what organization of knowledge is most efficient and make this common knowledge within the group. The current setup also abstracts from all conflicts of interest within the organization. If managers can extract rents, if they receive some monetary reward for their role, the resulting power struggle could hinder learning and the adoption of an optimal organization of knowledge. 


\section{References}

Bartling, B., Fehr, E. \& Herz, H. (2014). The intrinsic value of decision rights, Econometrica 82(6): 2005-2039.

Becker, G. S. \& Murphy, K. M. (1992). The division of labor, coordination costs, and knowledge, Quarterly Journal of Economics 107(4): 1137-1160.

Bloom, N., Eifert, B., Mahajan, A., McKenzie, D. \& Roberts, J. (2013). Does management matter? Evidence from India, Quarterly Journal of Economics 128(1): 1-51.

Bloom, N. \& Van Reenen, J. (2010). Why do management practices differ across firms and countries?, Journal of Economic Perspectives 24(1): 203-224.

Brandts, J. \& Cooper, D. J. (2006). A change would do you good ... An experimental study on how to overcome coordination failure in organizations, American Economic Review 96(3): 669-693.

Brandts, J. \& Cooper, D. J. (2007). It's what you say, not what you pay: An experimental study of manager-employee relationships in overcoming coordination failure, Journal of the European Economic Association 5(6): 1223-1268.

Brandts, J., Cooper, D. J. \& Weber, R. A. (2015). Legitimacy, communication, and leadership in the turnaround game, Management Science 61(11): 2627-2645.

Camerer, C. F. \& Weber, R. A. (2013). Experimental organizational economics, in R. Gibbons \& J. Roberts (eds), Handbook of Organizational Economics, Princeton University Press, pp. 213-262.

Chen, D. L., Schonger, M. \& Wickens, C. (2016). otree - an open-source platform for laboratory, online, and field experiments, Journal of Behavioral and Experimental Finance 9: $88-97$.

Crockett, S., Smith, V. L. \& Wilson, B. J. (2009). Exchange and specialization as a discovery process, Economic Journal 119: 1162-1188.

Dessein, W. \& Holden, R. (2019). Organizations with power-hungry agents, Columbia Business School Research Paper No. 17-90 pp. 1-52. 
Dominguez Martinez, S., Sloof, R. \& von Siemens, F. A. (2014). Monitored by your friends, not your foes: Strategic ignorance and the delegation of real authority, Games and Economic Behavior 85: 289-305.

Fehr, E., Herz, H. \& Wilkening, T. (2013). The lure of authority: Motivation and incentive effects of power, American Economic Review 103(4): 1325-1359.

Foster, L., Haltiwanger, J. \& Syverson, C. (2008). Reallocation, firm turnover, and efficiency: Selection on productivity or profitability, American Economic Review 98(1): 398-425.

Garicano, L. (2000). Hierachies and the organization of knowledge in production, Journal of Political Economy 108(5): 874-904.

Georgalos, K. \& Hey, J. (2020). Testing for the emergence of spontaneous order, Experimental Economics 23: 912-932.

Greiner, B. (2015). Subject pool recruitment procedures: Organizing experiments with ORSEE, Journal of the Economic Science Association 1(1): 114-125.

Hall, R. \& Jones, C. (1999). Why do some countries produce so much more output than others, Quarterly Journal of Economics 114(1): 83-116.

Kimbrough, E. O., Smith, V. L. \& Wilson, B. J. (2008). Historical property rights, sociality, and the emergence of impersonal exchange in long-distance trade, American Economic Review 98(3): 1009-1039.

Kimbrough, E. O., Smith, V. L. \& Wilson, B. J. (2010). Exchange, theft, and the social formation of property, Journal of Economic Behavior and Organization 74: 206-229.

Owens, D., Grossman, Z. \& Fackler, R. (2014). The control premium: A preference for payoff autonomy, American Economic Journal: Microeconomics 6(4): 138-161.

Sloof, R. \& von Siemens, F. A. (2017). Illusion of control and the pursuit of authority, Experimental Economics 20(3): 556-573.

Smyth, A. \& Wilson, B. J. (2019). No mere tautology: The division of labor is limited by the division of labor, Oxford Economic Papers pp. 1-28.

Syverson, C. (2004). Product substitutability and productivity dispersion, Review of Economics and Statistics 86(2): 534-550. 
van Huyck, J. B., Battalio, R. C. \& Beil, R. (1990). Tacit coordination games, strategic uncertainty, and coordination failure, American Economic Review 80(1): 234-248.

van Huyck, J. B., Gillette, A. B. \& Battalio, R. C. (1992). Credible assignments in coordination games, Games and Economic Behavior 4: 606-626.

Weber, R. A. (2006). Managing growth to achieve efficient coordination in large groups, American Economic Review 96(1): 114-126. 


\section{Appendix A: Figures}
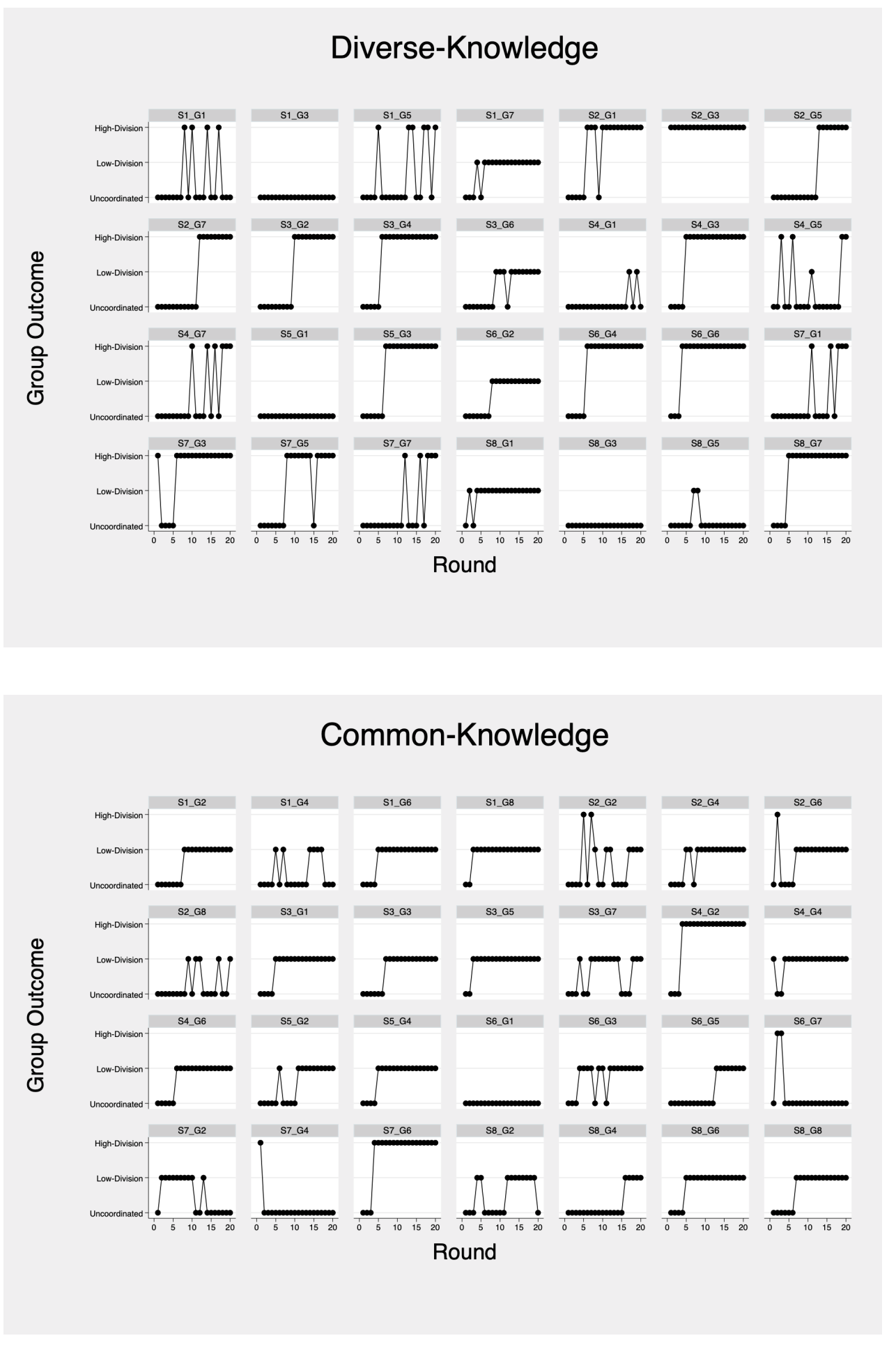

Figure 2: Individual Coordination Over Time.

Note: The figure shows individual coordination in each round and for all groups individually. 


\section{Appendix B: Power Preferences}

Fehr, Herz \& Wilkening (2013), Bartling, Fehr \& Herz (2014), Dominguez Martinez, Sloof \& von Siemens (2014), Owens, Grossman \& Fackler (2014), and Sloof \& von Siemens (2017) show empirically that some people have preferences for power, and Dessein \& Holden (2019) analyze theoretically how power preferences might affect organizational structure. In the following, we explore whether power preferences prevent groups from adopting Low-Division-of-Labor or complicate the adoption of High-Division-of-Labor. We conclude that power preferences do not seem to be behaviorally relevant in our experiment.

First, although the label "manager" might attract some participants, managers do not have real power in our setup because they cannot force workers to do anything or extract monetary payoffs from them. Second, power preferences cannot explain why some groups persistently coordinate on the inefficient Low-Division-of-Labor in Diverse-Knowledge. Thirdly, we do not see power struggles in the experiment. If participants fight to become managers, many groups should be uncoordinated because two or three members become managers. Figure 3 plots the number of managers in the groups over time. In the first round, only $14 \%$ and $11 \%$ of the groups have two managers in Diverse-Knowledge and Common-Knowledge. Looking only at the uncoordinated groups, we find two managers only in $15 \%$ and $12 \%$ of the groups in Diverse-Knowledge and Common-Knowledge. Throughout the experiment, we hardly ever observe groups with three managers in any round. 


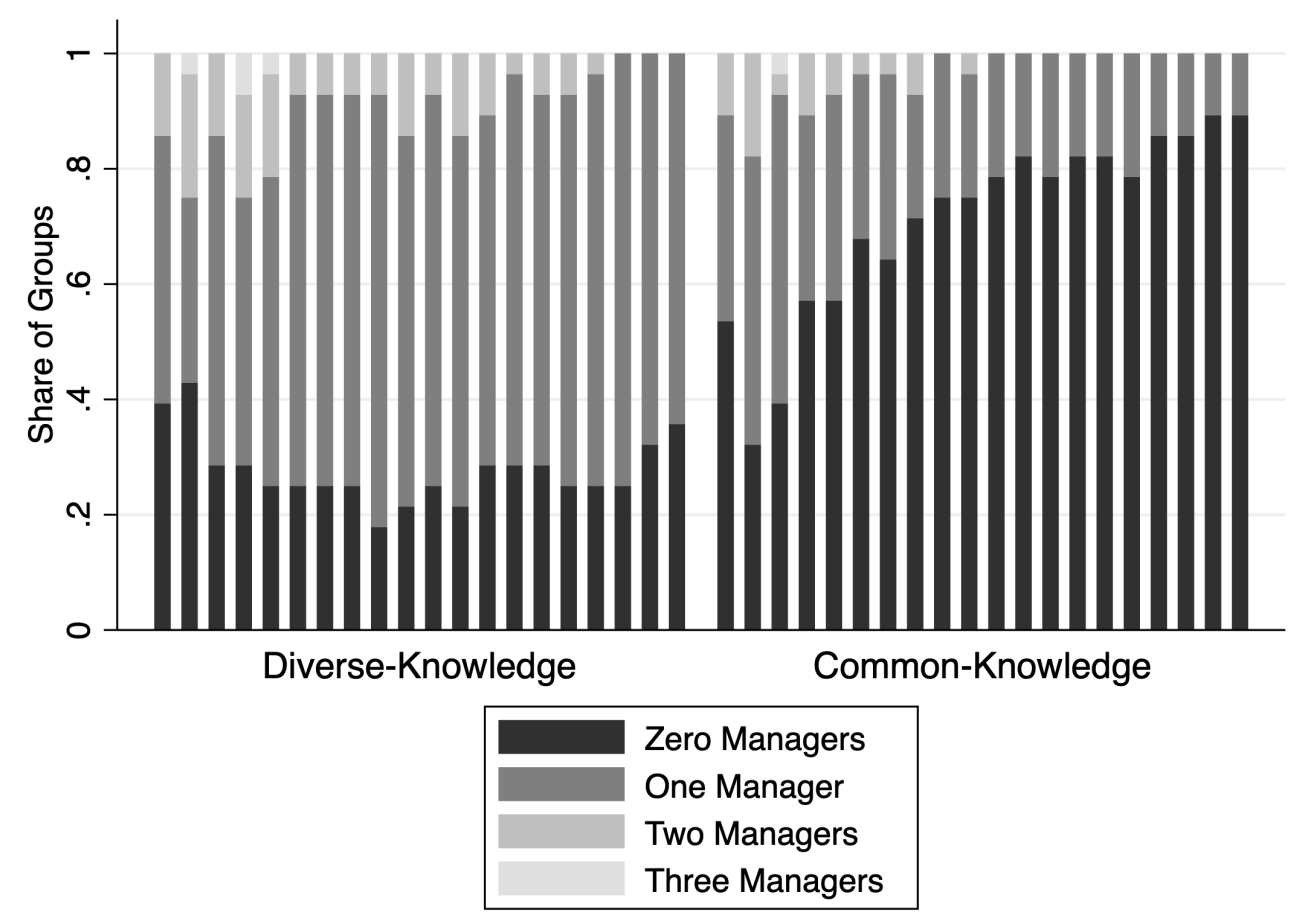

Figure 3: Occupational Choices Over Time.

Note: Distribution of groups with a particular number of managers, for all rounds and treatments.

Finally, we analyze the free-form text boxes in our final questionnaire to study power preferences' importance. We coded the variable "Power Preferences" that indicates whether some group participants just wanted to be a manager. Less than $2 \%$ of the participants mention something in some way related to power preferences. This finding confirms our above results that power preferences do not seem to matter in our experiment. 


\section{Appendix C: Instructions}

\section{Overview}

\section{Teams}

In this experiment, you will interact anonymously with two other participants in a team of three. Your randomly composed team will remain the same throughout the experiment. We assign a label to everyone in the team to be able to give accurate feedback. Therefore, each team has a group member triangle, square and circle.

\section{Rounds}

During the experiment, you can earn points for your team in a total of 20 rounds.

To do this, you must make the right decisions in your team.

All team members will receive the points earned by everyone for the team.

This means that all team members will have the same amount of points in the end.

The points earned will yield your earnings in this round.

\section{Payments}

At the end of the experiment we randomly choose one of the 20 rounds.

Hereby, each round is drawn with equal probability.

Your earnings from the experiment will be the points earned in this round. 100 points correspond to 50 euro cents.

In addition, you will receive $5,00 €$ for showing up on time.

\section{Team interaction in one round}

You will now learn how your team can earn points in each round.

To do this, you have to solve so-called "tasks" in the team.

These tasks are not actual tasks.

You do not need to apply or learn any real skills to solve them.

\section{Roles}

In each team, the team members can take on the role of an employee or a manager.

Employees are each assigned 100 tasks, which they may be able to complete themselves.

Managers are not assigned their own tasks, but they can help employees with uncompleted tasks.

Everyone in your team decides simultaneously whether they want to take on the role of an employee or a manager.

The role you choose will then be effective for that round.

In the next round all participants can choose their respective roles again. 


\section{Tasks}

Each employee is assigned 100 tasks in each round.

There are two different types of tasks, orange and silver.

Of the 100 tasks, 55 [75] tasks always have the task type orange.

The remaining 45 [25] tasks have the task type silver.

The orange task type is therefore more common than the silver task type.

\section{Solving tasks}

After choosing their role, everyone in the team decides simultaneously for which type of task they want to "prepare".

They do not yet know which roles the others in the team have chosen.

An employee can directly complete the tasks for whose task type he has prepared himself.

For the tasks that he cannot solve himself, he can send a request for help to his team.

Such a request for help results in communication costs of 25 points for the team.

In case of requests for help, a manager can solve the tasks for whose task type he has prepared himself.

In total, a manager or an employee can solve a maximum of 100 tasks in each round.

\section{Earnings}

For each solved task the team and therefore each team member earns 10 points. Any communication costs that may be incurred are deducted from this amount.

\section{Round 1 of the experiment}

Now the 1 st round of a total of 20 rounds begins.

You are the team member triangle/square/circle in your team for the whole experiment.

In each round all team members choose again whether they want to be employee or manager.

Likewise, each team member chooses again for which task type they want to prepare.

\section{Selection of the role in the team and preparation of a task type}

You must now decide what role you want to take on in your team for this round.

You must also decide which type of task you want to prepare for.

Employees are assigned 100 tasks in each round.

Of these, 55 [75] are orange tasks and 45 [25] are silver tasks.

Employees can complete the tasks for whose type they have prepared.

Managers are not assigned their own tasks, but they can help employees with uncompleted tasks.

What role do you want to take on in your team?

- Employee

- Manager

What type of task do you want to prepare for?

- Orange

- Silver 


\section{Your tasks}

(Employee) You are assigned 100 tasks.

Of these, 55 [75] are orange tasks and 45 [25] are silver tasks.

As you have prepared for the orange/silver task type, you can solve 55/45 [75/25] tasks.

You will therefore earn 550/450 [750/250] points for your team.

You must now decide whether you want to submit a request for help for the 45/55 [25/75] unsolved tasks in your team.

A help request generates communication costs of 25 points for your team.

These costs are incurred even if no manager can solve your tasks.

Without a help request, however, these tasks will certainly remain unsolved.

Would you like to ask for help in your team?

- Yes

- No

(Manager) Since you are in the role of a manager, no tasks are assigned to you.

\section{Help requests from your team members (Manager, example)}

You have prepared for task type silver.

Team member triangle is an employee and has requested help for 45 silver tasks.

You were able to help an employee to solve 45 tasks of type silver.

\section{Result of round 1 (example)}

\section{Behavior in the group}

You are the team member square in your team for the whole experiment.

You were a manager this round.

You have prepared for the task type silver.

You have not been assigned your own tasks as a manager.

There was a request for help in group 1.

In total you could help to solve 45 tasks.

Group member triangle was an employee.

He prepared for the task type orange.

He was assigned 55 orange tasks and 45 silver tasks.

So he could solve 55 tasks.

For the remaining tasks he asked for help.

Group member circle was an employee

He has prepared himself for the orange task type.

He has been assigned 55 orange tasks and 45 silver tasks.

He could therefore solve 55 tasks.

For the remaining tasks he did not ask for help. 


\section{Earnings in this round}

In your team 155 tasks could be solved.

By solving tasks, your team has thus achieved 1550 points.

There was 1 request for help, which resulted in communication costs of 25 points.

The group earnings less the costs are 1550 points -25 points $=1525$ points.

Each group member will receive 1525 points if this round is selected at the end.

\section{Final results (example)}

The main part of the experiment is now completed.

Round 1 was randomly selected to determine your payoff.

In this round you received 1525 points.

100 points correspond to 50 euro cents.

Including your participation fee of $5,00 €$, your payoff rounded up to 5 Eurocent is $12,65 €$.

Now you need to briefly fill out a few questionnaires.

Then we call you with the number of your computer to the front and pay you there. 